\title{
Short-Time of Rehydration is not Effective to Re-Establish Chlorophyll Fluorescence and Gas Exchange in Two Cowpea Cultivars Submitted to Water Deficit
}

\author{
Udson de Oliveira BARROS JUNIOR ${ }^{1}$, \\ Maria Antonia Machado BARBOSA ${ }^{2}$, Michael Douglas Roque LIMA ${ }^{1}$, \\ Gélia Dinah Monteiro VIANA², Allan Klynger da Silva LOBATO ${ }^{1 *}$ \\ ${ }^{1}$ Núcleo de Pesquisa Vegetal Básica e Aplicada, Universidade Federal Rural da Amazônia, Paragominas, \\ Brazil; udson_engflorestal@outlook.com; lima_florestal@outlook.com; allanllobato@yahoo.com.br(*correspondingauthor) \\ ${ }^{2}$ Departamento de Biologia Vegetal, Universidade Federal de Viçosa, Viçosa, \\ Brazil;suzymbarbosa@hotmail.com;gelia_agroviana@hotmail.com
}

\begin{abstract}
Low water supply frequently interferes on chlorophyll fluorescence and gas exchange. This study aimed to answer if a short-time of rehydration is efficient to re-establish chlorophyll fluorescence and gas exchange in cowpea plants. The experiment used four treatments (sensitive / water deficit, sensitive / control, tolerant / water deficit and tolerant / control). The sensitive and tolerant cultivars after water restriction had significant changes in gas exchange. On the third day, the stress caused lower for $P_{\mathrm{N}}$ and $g_{s}$ in sensitive cultivar of $67 \%$ and $45 \%$, respectively. After rehydration these parameters were not recovered significantly to two cultivars. In relation to chlorophyll fluorescence, water stress caused significant changes in all parameters evaluated of cultivars, being observed effects more intense on sensitive cultivar in the parameters $F_{\mathrm{v}} / F_{\mathrm{m}}(38 \%)$ and $F_{\mathrm{o}}(69 \%)$. Rehydration did not promote recovery of the values of $F_{\mathrm{v}} / F_{\mathrm{m}}$ and $F_{\mathrm{o}}$ to sensitive cultivar. Therefore, our study revealed that a short-time of rehydration is not effective to re-establish chlorophyll fluorescence and gas exchange in cowpea plants submitted to water deficit.
\end{abstract}

Keywords: pigments, photosynthesis, quantum yield of photosystem II, reactive oxygen species, water deficiency

\section{Introduction}

Low water supply frequently interferes on water relations of the plants and causes reversible alterations on stomatal mechanism $\left(g_{\mathrm{s}}\right)$, photosynthesis $\left(P_{\mathrm{N}}\right)$, transpiration $(E)$ and intercellular $\mathrm{CO}_{2}$ concentration $\left(C_{\mathrm{i}}\right)$, reflecting negatively on water use efficiency (WUE) and also on yield (Souza $e t$ al., 2004; Wang et al., 2003). Thus, the adequate work of the photosynthetic apparatus in plants under water deficit is extremely important aiming tolerance to water deficit (Zlatev, 2013).

Water deficit reduces the photochemical efficiency of photosystem II (PSII) and the transport rate of electrons used to photosynthesis, causing higher energy excess followed by photoinhibition of the PSII reaction center (Bai et al., 2008). In addition, this abiotic stress induces the overproduction of reactive oxygen species (ROS), with consequent increase in lipid peroxidation and electrolyte leakage of the chloroplast membranes (Catola et al., 2016).
Souza et al. (2004) reported increase in $F_{o}$ accompanied by reductions in $\mathrm{F}_{\mathrm{m}}$ and $\mathrm{F}_{\mathrm{v}} / \mathrm{F}_{\mathrm{m}}$ in $V$. unguiculata plants. Additionally, Pereira et al. (2016) studying six populations $V$. unguiculata under water deficit also found changes in chlorophyll fluorescence, being described reductions in $\mathrm{F}_{\mathrm{v}} / \mathrm{F}_{\mathrm{m}}$, $\Phi_{\text {PSII }}, \mathrm{qP}$ and ETR, and increases to EXC, NPQ and ETR $/ P_{\mathrm{N}}$. Based on this overview, our hypothesis is that the short-time of rehydration might recover the gas exchange and chlorophyll fluorescence modified by the water deficit. Therefore, this study aimed to answer if a short-time of rehydration is efficient to re-establish chlorophyll fluorescence and gas exchange in cowpea plants, being used two contrasting cultivars in relation to water deficit.

\section{Materials and Methods}

\section{Location and growth conditions}

The experiment was performed at the Paragominas Campus of the Universidade Federal Rural da Amazônia, Paragominas,

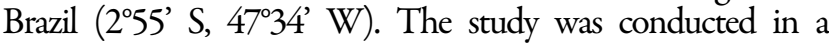


greenhouse under controlled temperature and humidity conditions; the minimum, maximum, and median temperatures were 23,32 and $26.5^{\circ} \mathrm{C}$, respectively. The air relative humidity during the experimental period varied between $60 \%$ and $80 \%$.

\section{Plants, containers and acclimation}

The seeds of Vigna unguiculata (L.) Walp were obtained from cultivar 'BR3-Tracuateua' and 'Pingo de Ouro 1-2'. The cultivars were chosen according to the characteristics of tolerance to water deficit verified by Bastos et al. (2011) evaluating twenty genotypes submitted to water deficit, being 'BR3-Tracuateua' sensitive to water deficit and 'Pingo de Ouro 1-2' tolerant. The seeds were germinated and grown in $1.2-\mathrm{L}$ pots $(0.15 \mathrm{~m}$ in height and $0.10 \mathrm{~m}$ in diameter) filled with a mixed substrate of sand and vermiculite in a 3:1 ratio. Plants were cultivated under semihydroponic conditions, and the pots had one hole at the bottom, which was covered with mesh to maintain the substrate and aerate the roots. Solution absorption occurred by capillarity; these pots were placed into other containers $(0.15 \mathrm{~m}$ in height and $0.15 \mathrm{~m}$ in diameter) containing $500 \mathrm{~mL}$ of distilled water for five d. Modified Hoagland and Arnon's (1950) solution was used as a source of nutrients; the ionic strength started at 50\% and was modified to $100 \%$ after one day. Subsequently, the nutrient solution remained at total ionic strength.

\section{Experimental design}

The experiment was set up using a completely randomized design with four treatments (sensitive / water deficit, sensitive / control, tolerant / water deficit and tolerant / control). The experiment was assembled with five replicates for each of four treatments, a total of 20 experimental units were used in the experiment, with one plant in each unit.

\section{Plant conduction, water deficit and rehydration}

The plants received the following macro- and micronutrients from the nutritive solution: $8.75 \mathrm{mmol} \mathrm{KNO}_{3}, 7.5 \mathrm{mmol}$ $\mathrm{Ca}\left(\mathrm{NO}_{3}\right)_{2} \cdot 4 \mathrm{H}_{2} \mathrm{O}, 3.25 \mathrm{mmol} \mathrm{NH} \mathrm{H}_{4} \mathrm{H}_{2} \mathrm{PO}_{4}, 1.5 \mathrm{mM} \mathrm{MgSO} 4.7$ $\mathrm{H}_{2} \mathrm{O}, \quad 62.50 \mu \mathrm{mol} \mathrm{KCl}, 31.25 \mu \mathrm{M} \mathrm{H}_{3} \mathrm{BO}_{3}, 2.50 \mu \mathrm{mol}$ $\mathrm{MnSO}_{4} \cdot \mathrm{H}_{2} \mathrm{O}, \quad 2.50 \quad \mu \mathrm{M} \quad \mathrm{ZnSO}_{4} 7 \mathrm{H}_{2} \mathrm{O}, \quad 0.63 \mu \mathrm{mol}$ $\mathrm{CuSO}_{4} .5 \mathrm{H}_{2} \mathrm{O}, 0.63 \mu \mathrm{mol} \mathrm{NaMoO}_{4} .5 \mathrm{H}_{2} \mathrm{O}$, and $250.0 \mu \mathrm{mol}$ $\mathrm{NaEDTAFe} \cdot 3 \mathrm{H}_{2} \mathrm{O}$. Twenty four-day-old plants were used to simulate the water deficit and rehydration, the solution was totally removed, being the root system placed in equal pots without water/solution, which was applied the water deficit by three day and one day after to establish the water/solution. During the study, the solutions were changed at 07:00h at 3-day intervals, with the $\mathrm{pH}$ adjusted to 5.5 using $\mathrm{HCl}$ or $\mathrm{NaOH}$. On day 28 of the experiment, physiological parameters were measured for all plants, and leaf tissues were harvested for biochemical analyses.

\section{Measurement of chlorophyllfluorescence}

The minimal fluorescence yield of the dark-adapted state $\left(\mathrm{F}_{0}\right)$, maximal fluorescence yield of the dark-adapted state $\left(\mathrm{F}_{\mathrm{m}}\right)$, variable fluorescence $\left(\mathrm{F}_{\mathrm{v}}\right)$, maximal quantum yield of PSII photochemistry $\left(\mathrm{F}_{\mathrm{v}} / \mathrm{F}_{\mathrm{m}}\right)$, effective quantum yield of PSII photochemistry ( $\Phi_{\text {PSII }}$ ), photochemical quenching coefficient $\left(\mathrm{q}_{\mathrm{P}}\right)$, nonphotochemical quenching (NPQ), electron transport rate (ETR), relative energy excess at the PSII level (EXC) and the ratio between electron transport rate and net photosynthetic rate $\left(\mathrm{ETR} / P_{\mathrm{N}}\right)$ were determined using an modulated chlorophyll fluorometer (model OS5p; Opti-Sciences). Chlorophyll fluorescence was measured using fully expanded leaves under light conditions. Preliminary tests determined the location of the leaf, the part of the leaf and the time required to obtain the greatest $\mathrm{F}_{\mathrm{v}} / \mathrm{F}_{\mathrm{m}}$ ratio; consequently, the third acropetal leaf from the middle third of the plant adapted to the dark for $30 \mathrm{~min}$ was used in the evaluation. The intensity and duration of the saturation light pulse were $7,500 \mu \mathrm{mol} \mathrm{m} \mathrm{m}^{-2} \mathrm{~s}^{-1}$ and $0.7 \mathrm{~s}$, respectively.

\section{Evaluation of gas exchange}

The net photosynthetic rate $\left(P_{\mathrm{N}}\right)$, transpiration rate $(E)$, stomatal conductance $\left(g_{s}\right)$, and intercellular $\mathrm{CO}_{2}$ concentration $\left(C_{\mathrm{i}}\right)$ were evaluated using an infrared gas analyser (model $\mathrm{LCPro}^{+}$; ADC BioScientific). These parameters were measured on the adaxial surface of fully expanded leaves that were collected from the middle region of the plant. The water-use efficiency (WUE) was estimated according to Ma et al. (2004), and the instantaneous carboxylation efficiency $\left(P_{\mathrm{N}} / C_{\mathrm{i}}\right)$ was calculated using the formula described by Aragão et al. (2012). Gas exchange was evaluated in all plants under constant conditions of $\mathrm{CO}_{2}$ concentration, photosynthetically active radiation, air-flow rate and temperature in a chamber set at $360 \mu \mathrm{mol} \mathrm{mol}^{-1} \mathrm{CO}_{2}$, $800 \mu \mathrm{mol}$ photons $\mathrm{m}^{-2} \mathrm{~s}^{-1}, 300 \mu \mathrm{mol} \mathrm{s} \mathrm{s}^{-1}$ and $28^{\circ} \mathrm{C}$, respectively, between 10:00 and 12:00 h.

\section{Leaf water potential}

The leaf water potential $\left(\Psi_{\mathrm{w}}\right)$ was measured using fully expanded leaves located in the middle region of the plant and exposed to light, during the period between 11:30 to 12:00 h, which corresponded to midday potential. To determinate the $\Psi_{w}$, one leaf per plant and five plants per treatment were measured using an analogue plant moisture system (PMS Instrument Company, model 600). This system is based on the pressure chamber technique (Scholander et al., 1964), and the procedure outlined by Turner (1988) was followed.

\section{Determination of superoxide concentration}

To determine $\mathrm{O}_{2}^{-}, 1 \mathrm{ml}$ of extract was incubated with 30 $\mathrm{mM}$ phosphate buffer [pH 7.6] and $0.51 \mathrm{mM}$ hydroxylamine hydrochloride for $20 \mathrm{~min}$ at $25{ }^{\circ} \mathrm{C}$. Then, $17 \mathrm{mM}$ sulphanilamide and $7 \mathrm{mM} \alpha$-naphthylamine were added to the incubation mixture for $20 \mathrm{~min}$ at $25^{\circ} \mathrm{C}$. After the reaction, an identical volume of ethyl ether was added and centrifuged at $3,000 \times \mathrm{g}$ for $5 \mathrm{~min}$. The absorbance was measured at $530 \mathrm{~nm}$ (Elstner and Heupel 1976).

\section{Extraction of nonenzymatic compounds}

Nonenzymatic compounds $\left(\mathrm{H}_{2} \mathrm{O}_{2}\right.$ and MDA) were extracted as described by Wu et al. (2006). Briefly, a mixture to extract $\mathrm{H}_{2} \mathrm{O}_{2}$ and MDA was prepared by homogenising $500 \mathrm{mg}$ of fresh leaf material in $5 \mathrm{~mL}$ of $5 \%(\mathrm{w} / \mathrm{v})$ trichloroacetic acid. Then, the samples were centrifuged at 15,000 $\times \mathrm{g}$ for $15 \mathrm{~min}$ at $3^{\circ} \mathrm{C}$ to collect the supernatant.

\section{Determination of hydrogen peroxide concentration}

To measure $\mathrm{H}_{2} \mathrm{O}_{2}, 200 \mu \mathrm{L}$ of supernatant and $1800 \mu \mathrm{L}$ of reaction mixture $(2.5 \mathrm{mM}$ potassium phosphate buffer [ $\mathrm{pH} 7.0]$ and $500 \mathrm{mM}$ potassium iodide) were mixed, and the absorbance was measured at $390 \mathrm{~nm}$ (Velikova et al., 2000). 
240

\section{Quantification of malondialdehyde concentration}

MDA was determined by mixing $500 \mu \mathrm{L}$ of supernatant with $1,000 \mu \mathrm{L}$ of the reaction mixture, which contained $0.5 \%$ $(\mathrm{w} / \mathrm{v})$ thiobarbituric acid in $20 \%$ trichloroacetic acid. The mixture was incubated in boiling water at $95^{\circ} \mathrm{C}$ for $20 \mathrm{~min}$, after which the reaction was terminated by placing the reaction container in an ice bath. The samples were centrifuged at 10,000 $\mathrm{xg}$ for $10 \mathrm{~min}$, and the absorbance was measured at $532 \mathrm{~nm}$. The nonspecific absorption at $600 \mathrm{~nm}$ was subtracted from the absorbance data. The MDA-TBA complex (red pigment) amount was calculated based on the method of Cakmak and Horst (1991), with minor modifications, and an extinction coefficient of $155 \mathrm{mM}^{-1} \mathrm{~cm}^{-1}$ was used.

\section{Determination of electrolyte leakage}

Electrolyte leakage was measured according to the method of Gong et al. (1998), with minor modifications. Fresh leaves (200 $\mathrm{mg}$ ) were cut into pieces $1 \mathrm{~cm}$ in length and placed in containers with $8 \mathrm{~mL}$ of distilled deionised water. The containers were incubated in a water bath at $40{ }^{\circ} \mathrm{C}$ for $30 \mathrm{~min}$, and the initial electrical conductivity of the medium $\left(\mathrm{EC}_{1}\right)$ was measured. Then, the samples were boiled at $95^{\circ} \mathrm{C}$ for $20 \mathrm{~min}$ to release the electrolytes. After cooling, the final electrical conductivity $\left(\mathrm{EC}_{2}\right)$ was measured (Gong et al., 1998). The percentage of electrolyte leakage was calculated using the formula $\mathrm{EL}(\%)=\left(\mathrm{EC}_{1} / \mathrm{EC}_{2}\right) \times$ 100.

\section{Determination of photosynthetic pigments}

The chlorophyll and carotenoid determinations were performed using $40 \mathrm{mg}$ of leaf tissue. The samples were homogenised in the dark with $8 \mathrm{~mL}$ of $90 \%$ methanol (Nuclear). The homogenate was centrifuged at $6,000 \times \mathrm{g}$ for $10 \mathrm{~min}$ at 5 ${ }^{\circ} \mathrm{C}$. The supernatant was removed, and the chlorophyll $a(\mathrm{Chl} a)$ and $b(\mathrm{Chl} b)$, and carotenoid (Car) and total chlorophyll (total $\mathrm{Chl}$ ) contents were quantified using a spectrophotometer (model UV-M51; Bel Photonics) according to the methodology of Lichtenthaler and Buschmann (2001).

\section{Data analysis}

The data were subjected to analysis of variance, and significant differences between the means were determined using the $\mathrm{F}$ test. Standard deviations were calculated for each treatment at all the times evaluated. The statistical analyses were performed using Assistat software.

\section{Results}

\section{Reductions in water potential promoted by water deficit}

Reductions in water potential promoted by water deficit. The $\Psi_{\mathrm{w}}$ presented significant reductions of $393 \%$ and $267 \%$ after three days of water deficit in sensitive and tolerant cultivars, respectively (Fig. 1). After rehydration, significant differences of $220 \%$ and $147 \%$ wereobserved when compared to control treatment of sensitive and tolerant cultivars, respectively.

\section{Insufficient recovery of the chlorophyll fluorescence after} rehydration

The water deficit induced significant reductions in $F_{\mathrm{v}} / F_{\mathrm{m}}$, $F_{\mathrm{o}}$ and $F_{\mathrm{m}}$ for both cultivars, in which the sensitive cultivar after

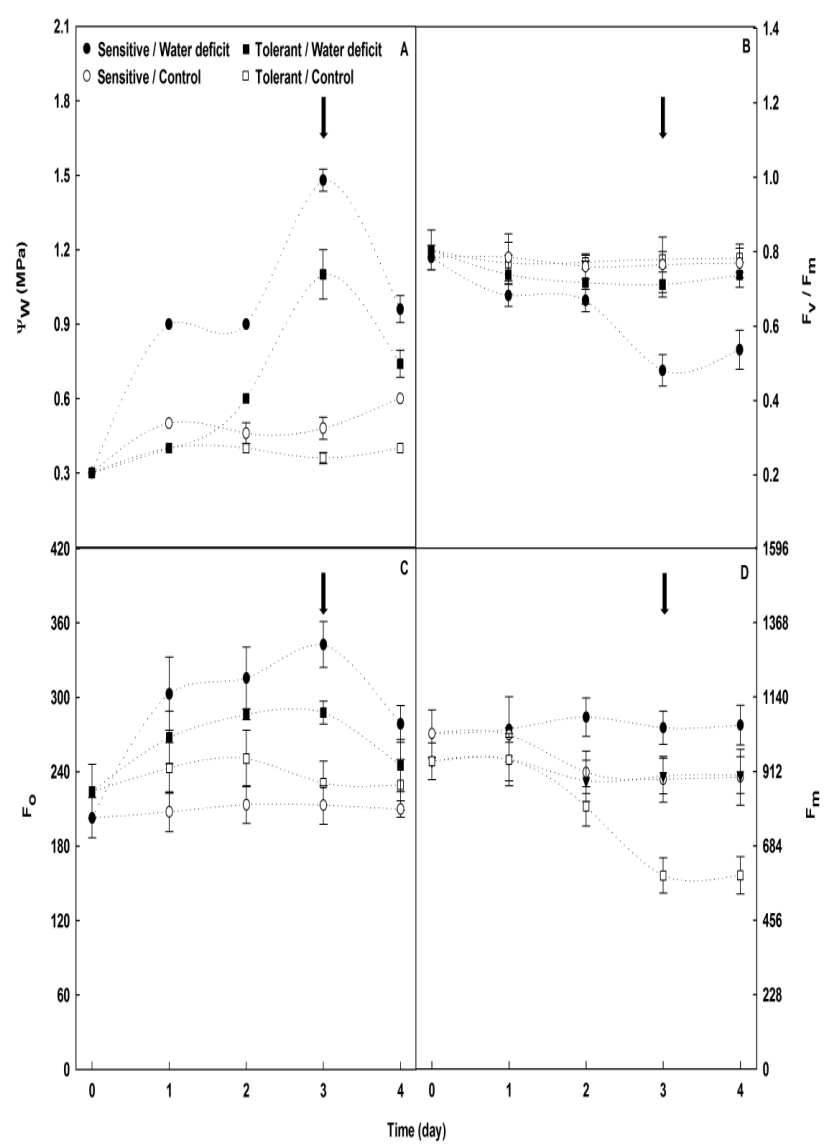

Fig. 1. Leaf water potential, maximal fluorescence yield of the dark-adapted state, minimal fluorescence yield of the darkadapted state and maximal quantum yield of PSII photochemistry in two cowpea cultivars submitted to water deficit and rehydration. Symbols described the mean values, bars represent the standard deviations from five repetitions and the arrow indicates the rehydration point

three days of water deficit had decreases of $38 \%, 69 \%$ and $37 \%$, respectively (Fig. 1). Rehydration did not promote recovery of the values of $F_{\mathrm{v}} / F_{\mathrm{m}}$ and $F_{\mathrm{o}}$ to sensitive cultivar, as well as not recovered $F_{\mathrm{m}}$ in both cultivars. The three days of water stress caused significant changes to $\Phi_{\text {PSII }}$ QP, NPQ, ETR, EXC and $\mathrm{ETR} / P_{\mathrm{N}}$ in both cultivars (Fig. 2), being observed effects more intense on sensitive cultivar.

\section{Short-time of rehydration not recovered gas exchange}

The sensitive and tolerant cultivars after water restriction had significant changes, being detected in the sensitive cultivar decreases by $67 \%, 31 \%, 45 \%, 52 \%$ and $80 \%$ for $P_{\mathrm{N}}, E, g_{s}$, WUE and $P_{\mathrm{N}} / C_{\mathrm{i}}$, respectively, and $63 \%$ increase for $C_{\mathrm{i}}($ Fig. 3). After rehydration these parameters were not recovered significantly to two cultivars.

\section{Overproduction of oxidative composts and cell damages after} water deficit

The $\mathrm{O}_{2}^{-}, \mathrm{H}_{2} \mathrm{O}_{2}, \mathrm{MDA}$ and EL concentrations of the two cultivars suffered more intense changes on the $3^{\text {rd }}$ day under water deficit, in which the sensitive cultivar showed increases of 


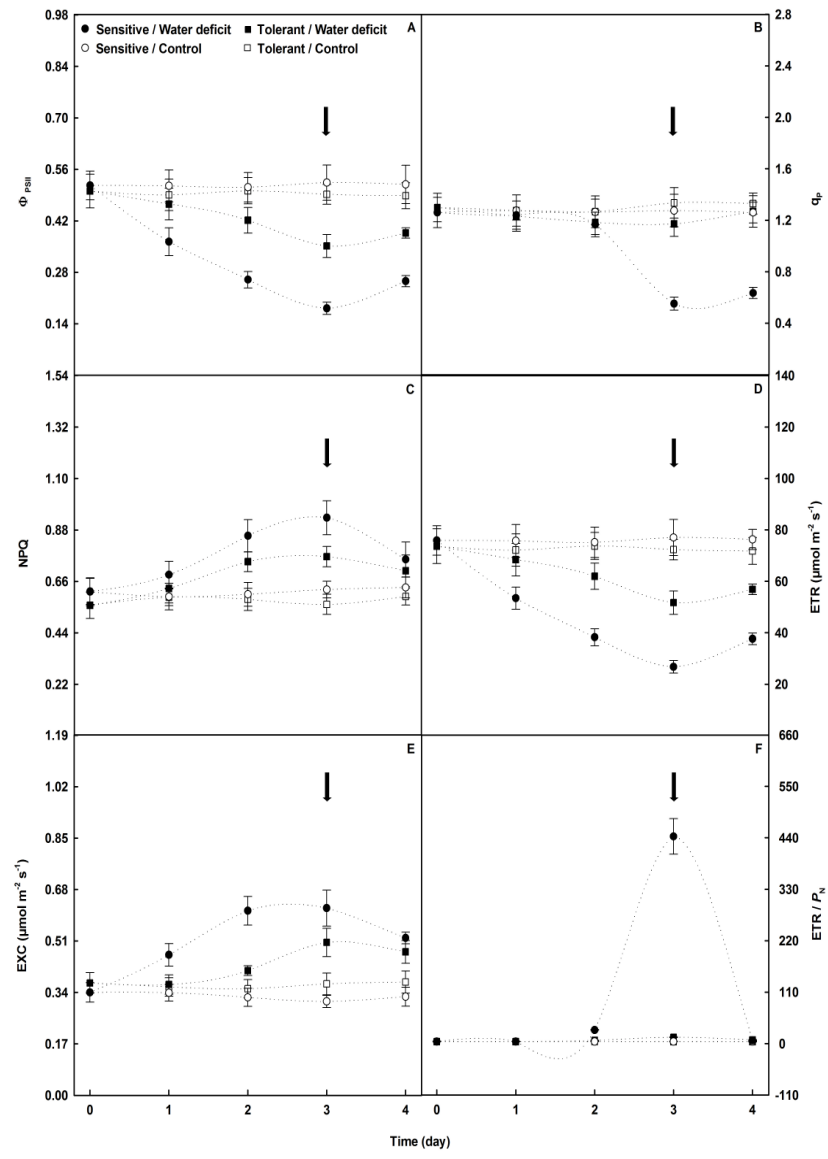

Fig. 2. Effective quantum yield of PSII photochemistry, photochemical quenching coefficient, nonphotochemical quenching, electron transport rate, relative energy excess at the PSII level and the ratio between electron transport rate and net photosynthetic rate in two cowpea cultivars submitted to water deficit and rehydration. Symbols described the mean values, bars represent the standard deviations from five repetitions and the arrow indicates the rehydration point

$227 \%, 142 \%, 140 \%$ and 35\%, respectively (Fig. 4). Rehydration not recovered $\mathrm{H}_{2} \mathrm{O}_{2}$ and MDA significantly in both cultivars, while tolerant cultivar had recovery only to $\mathrm{O}_{2}{ }^{-}$and EL.

\section{Water deficit reduced the photosynthetic pigments}

Plants under water deficit presented significant reductions in Chl $a, \mathrm{Chl} b$, total Chl and Car in both cultivars (Fig. 5), being more intense the effects on the sensitive cultivar. Rehydration did not allow Significant recovery to $\mathrm{Chl} b$ and the total Chl in sensitive cultivar.

\section{Discussion}

The reduction in $\Psi_{\mathrm{w}}$ is related to limited absorption and transport of water by the roots and water loss through $E$ (Grzesiak et al., 2006). This behavior promotes the loss of cellular turgor, higher stomatal resistance and decrease in osmotic potential. Decrease in $\Psi_{\mathrm{w}}$ was described by Miyashita et al. (2005) in Phaseolus vulgaris exposed to water deficit of 8 days.

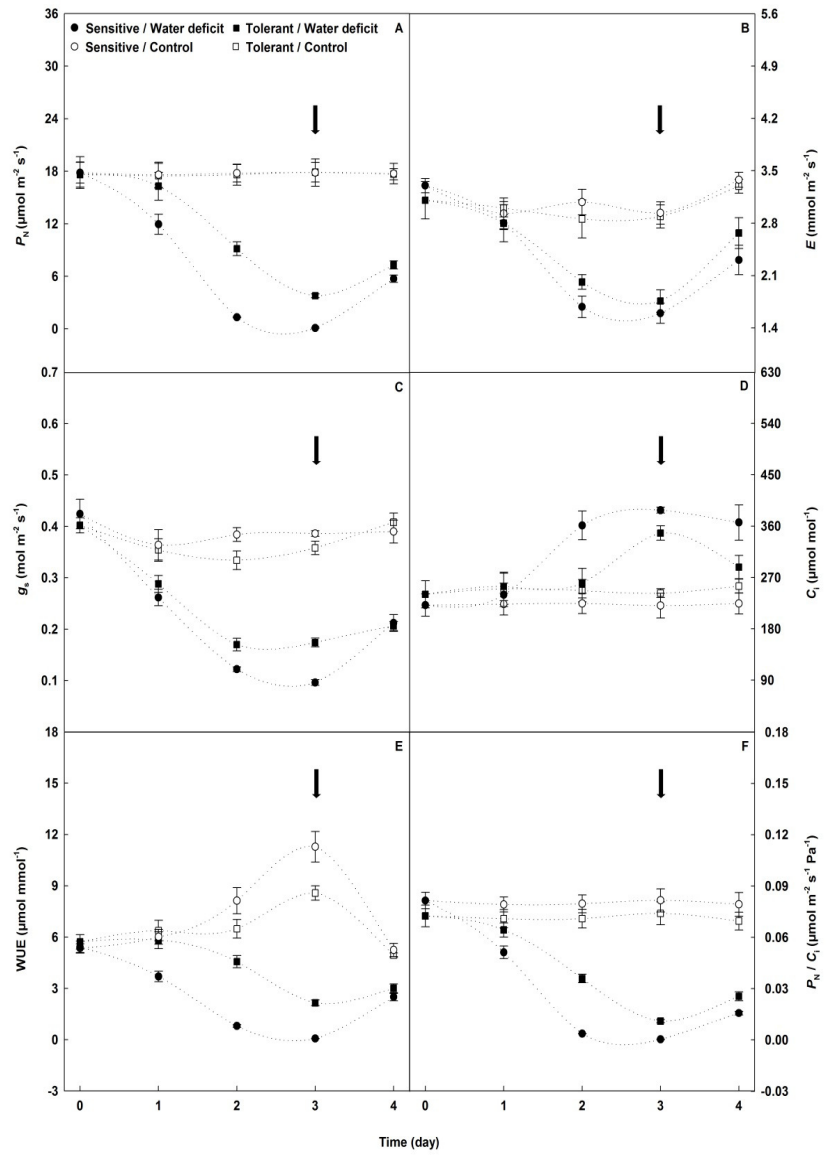

Fig. 3. Net photosynthetic rate, transpiration rate, stomatal conductance, intercellular $\mathrm{CO}_{2}$ concentration, water-use efficiency, and carboxylation instantaneous efficiency in two cowpea cultivars submitted to water deficit and rehydration. Symbols described the mean values, bars represent the standard deviations from five repetitions and the arrow indicates the rehydration point

The reductions in the $\mathrm{F}_{\mathrm{v}} / \mathrm{F}_{\mathrm{m}}$ and $\Phi_{\text {PSII }}$ values are related to decreases in the photochemical efficiency of the PSII, in which the water deficit reduces the capacity of the plastoquinone (PQ) to transport electrons (Drozdova et al., 2004). Increases in $F_{\mathrm{o}}$ accompanied by reductions in $\mathrm{F}_{\mathrm{m}}$ can be explained by the damages caused to the reaction center of PSII (Zlatev, 2009). The NPQ was increased in response to higher EXC values, indicating that $V$. unguiculata plants dissipated in the form of heat the excess energy. In addition, ETR $/ P_{\mathrm{N}}$ increased due to the increase previously described to NPQ, suggesting that occurred lower electron transfer to $\mathrm{CO}_{2}$ fixation, with consequent use of these electrons to photorespiration and other metabolic processes (Silva et al., 2012). Similar behavior was reported to EXC in Saccharum spp plants (Sales et al., 2015) and Jatropha curcas (Silva et al., 2015). Rivas et al. (2016) studying two cultivars of $V$. unguiculata, 'Pingo de Ouro 1-2' and Santo Inácio, found reductions for NPQ in $80 \%$ and $200 \%$, respectively, after 10 days of irrigation suspension. Similar results for ETR $/ P_{\mathrm{N}}$ were found by Santos et al. (2009) evaluating five genotypes of Phaseolus vulgaris after 10 days of water deficit. 
242

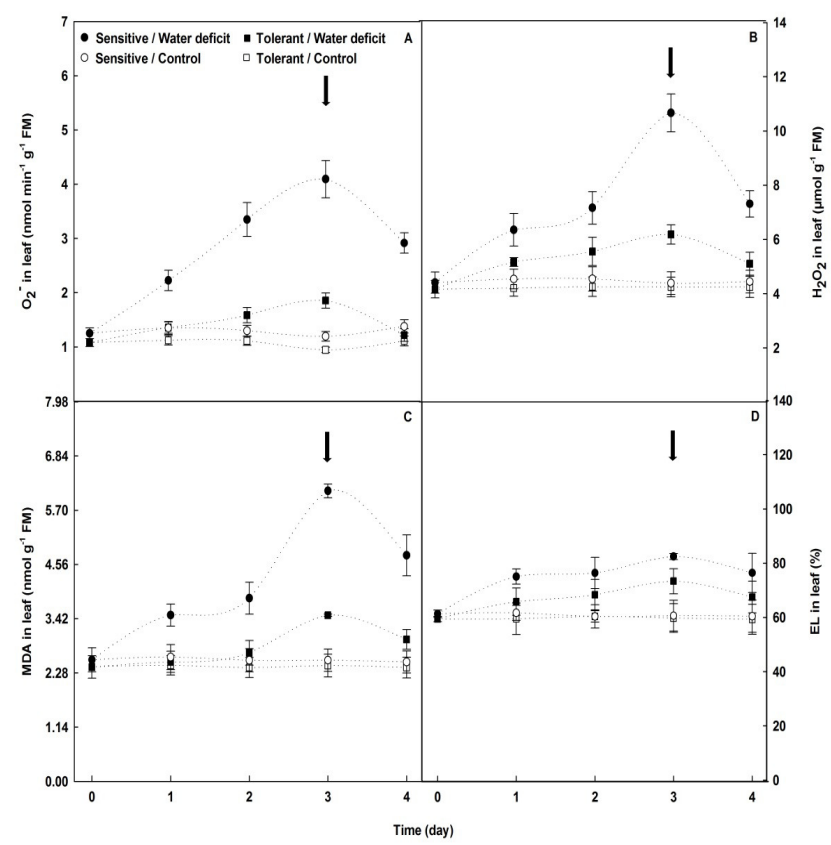

Fig. 4. Superoxide, hydrogen peroxide, malondialdehyde and electrolyte leakage in two cowpea cultivars submitted to water deficit and rehydration. Symbols described the mean values, bars represent the standard deviations from five repetitions and the arrow indicates the rehydration point

The reduction in $\mathrm{qp}_{\mathrm{p}}$ reveals lower photochemical efficiency in the energy conversion due to increase of NPQ, previously detected in this study. In addition, reductions in ETR indicate that the water deficit caused disorders in the electron transport chain present into membranes of thylakoids (Chagas et al., 2008). Catola et al. (2016) evaluating Punica granatum plants under water deficit found reduction of approximately $50 \%$ in q. Souza et al. (2004) studying $V$. unguiculata plants reported reductions of $82 \%$ and $72 \%$ for qp and ETR, respectively, after two days of water restriction, corroborating our results.

The water deficit induced lower $P_{\mathrm{N}}$ and $E$, and had as consequence decrease in the absorption and diffusion of $\mathrm{CO}_{2}$ inside the plant, besides to promote $\mathrm{CO}_{2}$ accumulation in the mesophyll region (Dutra et al., 2015), corroborating with increases detected to $C_{\mathrm{i}}$ in the sensitive cultivar. Decreases in $P_{\mathrm{N}}$ $(83 \%)$ and $E(85 \%)$ were reported by Endres et al. (2010) in $V i g n a$ unguiculata plants under water deficit conditions. For $C_{\mathrm{i}}$, Silva et al. (2010) evaluating Vigna unguiculata behavior in three irrigation regimes $(25 \%, 50 \%$ and $100 \%)$ detected higher values reported in treatment with lower water regime.

The decrease described to $P_{\mathrm{N}} / C_{\mathrm{i}}$ was influenced by the reduction in the $\mathrm{CO}_{2}$ absorption $\left(P_{\mathrm{N}}\right)$ and reductions in the ETR observed in this study. The decrease in ETR interferes on the supplies of ATP and NADPH, that will be used in fixation reactions of $\mathrm{CO}_{2}$ (Zlatev, 2013), resulting in the increase of the intercellular $\mathrm{CO}_{2}$ concentration $\left(C_{\mathrm{i}}\right)$ due this molecule not be fixed into Calvin cycle. The decrease obtained to WUE is explained by the reduction induced by water deficit mainly in $P_{\mathrm{N}}$ and also $E$, because this variable is obtained from the ratio between $P_{\mathrm{N}}$ and $E$.

The increases in $\mathrm{O}_{2}{ }^{-}$and $\mathrm{H}_{2} \mathrm{O}_{2}$ reveal the water limitation into plant cells, and consequent formation of reactive oxygen

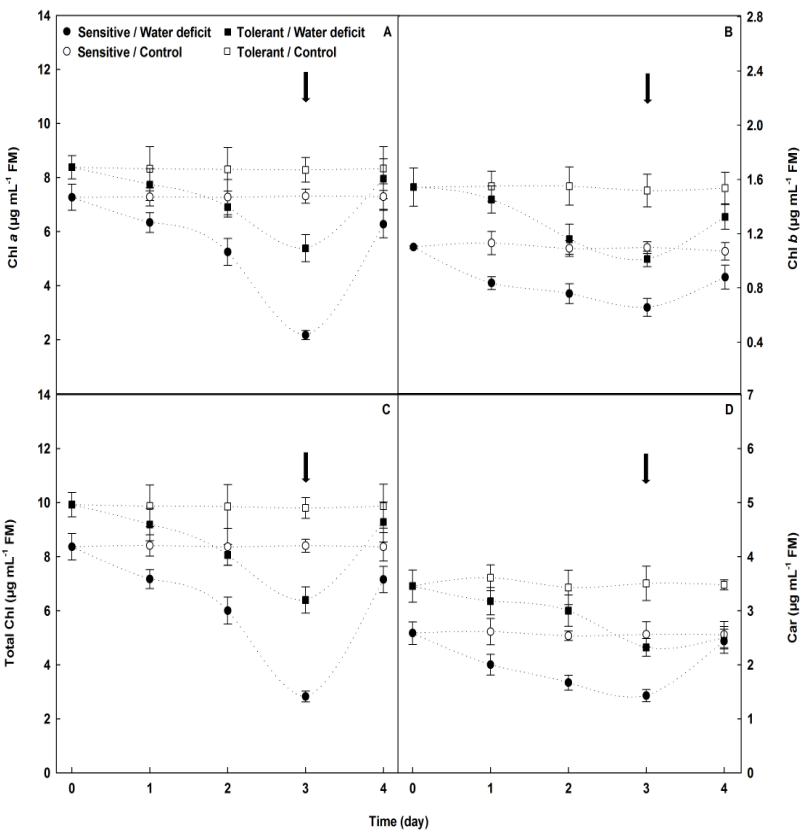

Fig. 5. Chlorophyll $a$, chlorophyll $b$, total chlorophyll and carotenoids in two cowpea cultivars submitted to water deficit and rehydration. Symbols described the mean values, bars represent the standard deviations from five repetitions and the arrow indicates the rehydration point

species (ROS), being that these composts promote the lipid peroxidation (Siddiqui et al., 2015), and induce the deterioration of the membranes, described by the increases of MDA and EL. Increases in ROS levels under water deficit conditions are associated with low efficiency in the excitation energy dissipation, through the photosynthetic apparatus, which it is considered an important source of overproduction of ROS under abiotic stress (Hura et al., 2015).

These results indicate that water deficiency resulted in an inhibition of the synthesis and/or degradation of the chlorophylls, as well as proteins involved in chloroplast synthesis, possibly to prevent the excessive absorption of UV radiation, during progressive stress (Jin et al., 2015). The recovery of pigments in the tolerant cultivar after rehydration is an indication that was recovered the physiological competence, after significant losses of water fraction in tissues. Trujillo et al. (2013) also observed negative impacts on the pigments of two cultivars of Phaseolus vulgaris after eight days of water deficit, and it observed a slight recovery of these parameters after one day of rehydration, corroborating the results obtained in this study.

\section{Conclusions}

Our results described that both cultivars after water restriction suffered significant changes in gas exchange and chlorophyll fluorescence, being more intense in sensitive cultivar. Additionally, this study revealed that a short-time of rehydration is not effective to reestablish chlorophyll fluorescence and gas exchange in cowpea plants submitted to water deficit. 


\section{Acknowledgements}

This research had financial support from Fundação Amazônia de Amparo a Estudos e Pesquisas (FAPESPA/Brazil), Universidade Federal Rural da Amazônia (UFRA/Brazil) Conselho Nacional de Desenvolvimento Científico e Tecnológico $(\mathrm{CNPq} / \mathrm{Brazil})$ to Lobato $\mathrm{AKS}$, as well as Barros Junior UO and Lima MDR were supported by undergraduate scholarships also from Conselho Nacional de Desenvolvimento Científico e Tecnológico (CNPq/Brazil).

\section{References}

Aragão RM, Silva EN, Vieira CF, Silveira JAG (2012). High supply of $\mathrm{NO}_{3}-$ mitigates salinity effects through an enhancement in the efficiency of photosystem II and $\mathrm{CO} 2$ assimilation in Jatropha curcas plants. Acta Physiologiae Plantarum 34(6):2135-2143.

Badawi GH, Yamauchi Y, Shimada E, Sasaki R, Kawano N, Tanaka K (2004). Enhanced tolerance to salt stress and water deficit by overspressing superoxide dismutase in tobacco (Nicotiana tabacum) chloroplasts. Plant Science 166(4):919-928.

Bai J, Xu DH, Kang HM, Chen K, Wang G (2008). Photoprotective function of photorespiration in Reaumuria soongorica during different levels of drought stress in natural high irradiance. Photosynthetica 46(2):232-237.

Bastos EA, Nascimento SP, Silva EM, Freire Filho FR, Gomide RL (2011). Identification of cowpea genotypes for drought tolerance. Revista Ciência Agronômica 42:100-107.

Cakmak I, Horst WJ (1991). Effect of aluminum on lipid peroxidation, superoxide dismutase, catalase, and peroxidase activities in root tips of soybean (Glycine max). Physiologia Plantarum 83(3):463-468.

Catola E, Marino G, Emiliani G, Huseynova T, Musayev M, Akparov Z, Maserti BE (2016). Physiological and metabolomic analysis of Punica granatum (L.) under drought stress. Planta 243(2):441-449.

Chagas RM, Silveira JAG, Ribeiro RV, Vitorello VA, Carrer H (2008). Photochemical damage and comparative performance of superoxide dismutase and ascorbate peroxidase in sugarcane leaves exposed to paraquat-induced oxidative stress. Pesticide Biochemistry Physiology 90:181-188.

Drozdova IS, Pustovoitova TN, Dzhibladze TG, Barabanshchikova NS, Zhdanova NE, Maevskaya SN, Bukhov NG (2004). Endogenous control of photosynthetic activity during progressive drought: Influence of final products of photosynthesis. Russian Journal of Plant Physiology 51(5):668-675.

Dutra AF, Melo AS, Filgueiras LMB, Silva ARF, Oliveira IM, Brito MEB (2015). Physiologic parameters and yield components of cowpea grown under water deficit. Revista Brasileira de Ciências Agrárias 10(2):189-197.

Elstner EF, Heupel A (1976). Inhibition of nitrite formation from hydroxylammoniumchloride: A simple assay for superoxide dismutase. Analytical Biochemistry 70(2):616-620.

Endres L, Souza JL, Teodoro I, Marroquim PMG, Santos CM, Brito JED (2010). Gas exchange alteration caused by water deficit during the bean reproductive stage. Revista Brasileira de Engenharia Agricola e Ambiental 14(1):11-16.
Gong M, Li YJ, Chen SZ (1998). Abscisic acid-induced thermotolerance in maize seedilings is mediated by calcium and associated with antioxidant systems. Journal of Plant Physiology 153(3-4):488-496.

Grzesiak MT, Grzesiak S, Skoczowski A (2006). Changes of leaf water potential and gas exchange during and after drought in triticale and maize genotypes differing in drought tolerance. Photosynthetica 44(4):561-568.

Hoagland DR, Arnon DI (1950). The water culture method for growing plants without soils. California Agricultural Experimental Station, Berkeley.

Hura T, Hura K, Ostrowska A, Dziurka K (2015). Rapid plant rehydration initiates permanent and adverse changes in the photosynthetic apparatus of triticale. Plant Soil 397:127-145.

Jin R, Shi H, Han C, Zhong B, Wang Q, Chan Z (2015). Physiological changes of purslane (Portulaca oleracea L.) after progressive drought stress and rehydration. Scientia Horticulturae 194:215-221.

Lichtenthaler HK, Buschmann C (2001). Chlorophylls and carotenoids: Measurement and characterization by UV-VIS spectroscopy. Current Protocols in Food Analytical Chemistry, $431-438$.

Ma JF, Mitani N, Nagao S, Konishi S, Tamai K, Iwashita T, Yano M (2004). Characterization of the silicon uptake system and molecular mapping of the silicon transporter gene in rice. Plant Physiology 136(2):3284-3289.

Miyashita K, Tanakamaru S, Maitani T, Kimura K (2005). Recovery responses of photosynthesis, transpiration, and stomatal conductance in kidney bean following drought stress. Environmental and Experimental Botany 53(2):205-214.

Pereira TS, Lima MDR, Paula LS, Lobato AKS (2016). Tolerance to water deficit in cowpea populations resulting from breeding program: Detection by gas exchange and chlorophyll fluorescence. Indian Journal of Plant Physiology 21(2):171-178.

Rivas R, Falcão HM, Ribeiro RV, Machado EC, Pimentel C, Santos MG (2016). Drought tolerance in cowpea species is driven by less sensitivity of leaf gas exchange to water deficit and rapid recovery of photosynthesis after rehydration. South African Journal of Botany, 103:101-107.

Scholander PF, Hammel HT, Hemmingsen EA, Bradstreet ED (1964). Hydrostatic pressure and osmotic potential of leaves in mangroves and some other plants. Proceeding of Natural Academic Science 52(1):119-125.

Sales CRG, Marchiori PER, Machado RS, Fontenele AV, Machado EC, Silveira JAG, Ribeiro RV (2015). Photosynthetic and antioxidant responses to drought during the sugarcane ripening. Photosynthetica 53(4):547-554.

Santos MG, Ribeiro RV, Machado EC, Pimentel C (2009). Photosynthetic parameters and leaf water potential of five common bean genotypes under mild water deficit. Biologia Plantarum 53(2):229-236.

Siddiqui MH, Al-Khaishany MY, Al-Qutami MA, Al-Whaibi MH, Grover A, Ali HM, Al-Wanibi MS, Bukhari NA (2015). Response of different genotypes of faba bean plant to drought stress. International Journal of Molecular Sciences 16(5):10214-10227. 
244

Silva CDS, Santos PAA, Lira JMS, Santana MC, Silva Júnior CD (2010). Daily course of gas exchange in plants of cowpea subjected to water deficit. Revista Caatinga 23(4):7-13.

Silva EN, Ribeiro RV, Ferreira-Silva SL, Vieira AS, Ponte LFA, Silveira JAG (2012). Coordinate changes in photosynthesis, sugar accumulation and antioxidative enzymes improve the performance of Jatropha curcas plants under drought stress. Biomass \& Bioenergy 45:270-279.

Silva EN, Silveira JAG, Ribeiro RV, Vieira SA (2015). Photoprotective function of energy dissipation by thermal processes and photorespiratory mechanisms in Jatropha curcas plants during different intensities of drought and after recovery. Environmental and Experimental Botany 110:36-45.

Souza RP, Machado EC, Silva JAB, Lagôa AMMA, Silveira JAG (2004). Photosynthetic gas exchange, chlorophyll fluorescence and some associated metabolic changes in cowpea (Vigna unguiculata) during water stress and recovery. Environmental and Experimental Botany 51:45-56.

Trujillo I, Rivas M, Castrillo M (2013). Leaf recovery responses during rehydration after water deficit in two bean (Phaseolus vulgaris L.) cultivars. Journal of Plant Interactions 8(4):360-369.
Turner NC (1988). Measurement of plant water status by the pressure chamber technique. Irrigation Science 9(4):289-308.

Velikova V, Yordanov I, Edreva A (2000). Oxidative stress and some antioxidant systems in acid rain-treated bean plants: Protective role of exogenous polyamines. Plant Science 151(1):59-66.

Wang W, Vinocur B, Altman A (2003). Plant responses to drought, salinity and extreme temperatures: Towards genetic engineering for stress tolerance. Planta 218(1):1-14.

Wu QS, Xia RX, Zou YN (2006). Reactive oxygen metabolism in mycorrhizal and non-mycorrhizal citrus (Poncirus trifoliata) seedlings subjected to water stress. Journal of Plant Physiology 163(11):1101-1110.

Zlatev Z (2009). Drought-induced changes in chlorophyll fluorescence of young wheat plants. Biotechnology \& Biotechnological Equipment 23:438-441.

Zlatev ZS (2013). Drought-induced changes and recovery of photosynthesis in two bean cultivars (Phaseolus vulgaris L.). Emirates Journal of Food and Agriculture 25(12):1014-1023. 